\title{
Nanoparticles as antifungal additives for indoor water borne paints
}

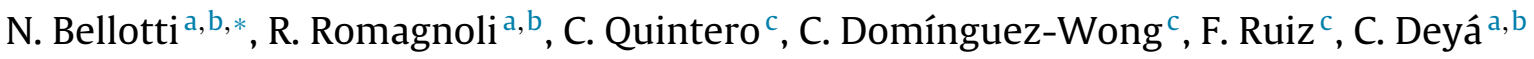 \\ a CONICET, Centro de Investigación y Desarrollo en Tecnología de Pinturas (CIDEPINT)-CICBA-CONICET, La Plata, Argentina \\ b Universidad Nacional de La Plata, La Plata, Argentina \\ c Universidad Autónoma de San Luis Potosí, San Luis Potosí, Mexico
}

\section{A R T I C L E I N F O}

\section{Article history:}

Received 16 October 2014

Received in revised form 25 February 2015

Accepted 10 March 2015

\section{Keywords:}

Nanoparticles

Antimicrobial coating

Biodeterioration

Biocide

Antifungal

\begin{abstract}
A B S T R A C T
There are nanotechnology-based materials that can be used as antimicrobial additives in different applications such as water-borne paints. Antimicrobial paints are important tool in order to avoid indoor biological colonization and therefore prevent paint bio-deterioration and health problems in people and pets. These paints would have application in kitchens, bathrooms and hospitals. The present study evaluated the incorporation of silver (of two different sizes), copper and zinc oxide nanoparticles in indoor waterborne paints and the bio-resistance imparted by them. The antifungal activity of nanoparticles is a less studied topic in relation to the antibacterial activity but is no less important from the environmental point of view. Molds that grow in indoor environments contribute significantly with bioaerosol formation and therefore on air contamination and human health deterioration. In this sense, this research evaluated the nanoparticles' antifungal activity using previously isolated fungi, Chaetomium globosum and Alternaria alternata, on solid medium. Then, the bio-resistance of acrylic paints, with nanoparticles incorporated, was evaluated in Petri dishes and observations were made using scanning electron microscopy. The better results were obtained with the paint that contained silver with the smaller size $(10 \mathrm{~nm})$.
\end{abstract}

(c) 2015 Elsevier B.V. All rights reserved.

\section{Introduction}

Mold can grow on wide variety of materials when sufficient moisture is available generating great numbers of spores, cell fragments, allergens, mycotoxins, endotoxins, $\beta$-glucans and volatile organic compounds [1-3]. An excess level of any of these agents in the indoor environment is a potential health hazard; therefore persistent microbial growth should be avoided or minimized [4]. In this sense, exposure to microbial contaminants has been associated with respiratory symptoms, allergies, asthma and immunological reactions and associated with the $20 \%$ of the documented infected cases with sanitary assistance [5-10]. Furthermore, molds growth affects materials causing their deterioration [5,7,9,11]. Wall waterborne paints, commonly acrylic-based, are a target to microorganisms due to the fact that they contain cellulosic compounds as thickeners. These compounds can be used by the microorganisms as carbon source producing degradation of the

\footnotetext{
* Corresponding author at: CONICET, Centro de Investigación y Desarrollo en Tecnología de Pinturas (CIDEPINT)-CICBA-CONICET, La Plata, Argentina. Tel.: +54 2214831142.

E-mail address: pinturashigienicas@cidepint.gov.ar (N. Bellotti).
}

paint: stains, color changes, chalking and adhesion loosening can be seen in an attacked paint.

Antimicrobial paints have the main objective to avoid or inhibit microbiological colonization and further growth often due to the incorporation of active agents named biocides [9,12]. The new tendencies in biocides formulation are directed to replace the traditional organochlorades and organometallic compounds by others with less environmental impact $[9,13,14]$. Antimicrobial coatings help to control infections propagation in health care centers and public places [7] and, despite they do not eliminate such infections transmittal they have the capacity to reduce it significantly [15-17].

Lots of compounds based on nanotechnology can be used as antimicrobial agents for different plastic matrixes, textiles, cosmetics, ceramics, paints, etc. [18]. Selection of appropriate materials is an important key to formulate these kind of coatings, taking this into account, nanomaterials as bioactive additives are promising $[19,20]$. The wide nanoparticles bioapplication is due to their excellent antibacterial activity on several gram positive and negative bacteria [21]. Silver nanoparticles (NP) exert more efficient than ions and silver salts in mediating their antimicrobial activity $[22,23]$. Usually, $\mathrm{Ag}^{+}$ions are efficient bactericides in low concentrations as low as about $0.001-0.05 \mu \mathrm{g} / \mathrm{mL}$, much lower than the doses for silver toxicity to human cells [24]. Furthermore, published data that examined antibacterial effect of copper and zinc 
oxide against bacterial biofilm revealed, in certain cases, significant reduction of bacterial growth [24-26].

In the present work, the biocide action of silver (AgA and AgG), copper $(\mathrm{Cu})$ and zinc oxide $(\mathrm{ZnO}) \mathrm{NP}$ incorporated in interior waterborne paints was evaluated; the size of silver nanoparticles was $10 \mathrm{~nm}(\mathrm{AgA})$ and $62 \mathrm{~nm}(\mathrm{AgG})$, of while the size of copper and zinc oxide were 20 and $40-50 \mathrm{~nm}$, respectively. Moreover, the $\mathrm{Ag}$ nanoparticles were obtained by environmental friendly route using gallic acid as a reducing agent [27]. Gallic acid is a renewable source as it is widespread natural product often characterized by substantial accumulations in certain tissues like young leaves of tea plant (Camellia sinensis) [28].

The antifungal activity of the NP was evaluated in solid media employing Alternaria alternata and Chaetomium globosum as aggressive fungi. Besides, bio-resistances assays were done on agarized media by a procedure based on ASTM D 5590 standard [29].

The molds were selected for their ability to grow on paint films and negative impact on human health $[30,31]$. In this sense, Alternaria and Chaetomium are able to produce a variety of different compounds including mycotoxins, which are toxic to mammals, and cellulolytic compounds that deteriorate the water-based paints as they degrade the cellulosic thickeners employed in paint formulation [30,31].

In order to increase the efficiency of the paint, the concentration of the NP was increased obtaining better results, especially in the case of AgA. Scanning electron microscopy (SEM), low vacuum mode, was employed to observe the paint surface exposed to the fungi in the case of the more efficient NP.

Bright and color change of the paints after the addition of the NP were evaluated too.

\section{Methodology}

\subsection{Nanoparticles preparation}

$\mathrm{AgA}$ : An aqueous solution was prepared dissolving $\mathrm{AgNO}_{3}$, $0.001 \mathrm{M}$ in $100 \mathrm{~mL}$ of deionized water. Later on, $10 \mathrm{~mL}$ of deionized water containing $0.01 \mathrm{~g}$ of gallic acid were added and the solution was placed under magnetic stirring; the $\mathrm{pH}$ value was increased up to 11 with the addition of $\mathrm{NH}_{4} \mathrm{OH}$ [32].

$\mathrm{AgG}$ : The synthesis was similar to the described before for AgA, but after the addition of gallic acid, the solution was irradiated with UV light $(254 \mathrm{~nm}, 15 \mathrm{~W})$ for $30 \mathrm{~min}$. After that, the solution was heated $30 \mathrm{~min}$ at $80^{\circ} \mathrm{C}$ [32].

$\mathrm{Cu}$ : Copper nanoparticles were synthesized with a precipitation method by using an aqueous solution of $\mathrm{CuSO}_{4}$ and ethylenediamine as precursors, then, a saturated solution of $\mathrm{NaBH}_{4}$ was added until copper precipitated with a black color. The nanoparticles obtained were washed with ethyl alcohol [33].

$\mathrm{ZnO}$ : A $0.05 \mathrm{M}$ solution of $\mathrm{ZnCl}_{2}$ was prepared and $2 \mathrm{~mL}$ of $\mathrm{HCl}$, $0.1 \mathrm{M}$ were added. The solution was heated up to $75^{\circ} \mathrm{C}$ with the addition of $5 \mathrm{~g}$ of dextrin as stabilizer. The solution acquired a black, opaque color. When the temperature of the solution decreased to $25^{\circ} \mathrm{C}$, an aqueous solution of $\mathrm{NaOH}(1 \mathrm{M})$ was added.

\subsection{Nanoparticles characterization}

The nanoparticles were characterized with UV-vis spectroscopy using an USB4000 UV-Vis spectrometer from Ocean Optics Inc. and dynamic light scattering (DLS) technique to confirm particle size distribution. Size distribution measurements were made in triplicate with a Malvern Zetasizer Nano ZS Instruments operating with a He-Ne laser at a wavelength of $633 \mathrm{~nm}$ and a detection angle of $90^{\circ}$; all samples were analyzed for $60 \mathrm{~s}$ at $25^{\circ} \mathrm{C}$. To confirm shape, each sample was diluted with deionized water and $50 \mu \mathrm{L}$ of each suspension was placed on a formvar-coated copper grid for transmission electron microscopy (TEM). All samples were analyzed by TEM with a JEOL JEM-1230 at an accelerating voltage of $100 \mathrm{kV}$ and X-ray diffraction (XRD) using GBC MMA SPELLMAN.

\subsection{Fungi isolation and identification}

Two fungi were collected by swabbing from paint films exposed to indoors environment in La Plata city ( $34^{\circ} 54^{\prime} \mathrm{S}$ and $57^{\circ} 55^{\prime} \mathrm{W}$ ) [34]. The culture media (DG-18) for the fungal growth were: $0.5 \mathrm{~g}$ protease peptone, $1.0 \mathrm{~g}$ glucose, $0.1 \mathrm{~g} \mathrm{KH}_{2} \mathrm{PO}_{4}, 0.05 \mathrm{~g} \mathrm{MgSO} \mathrm{M}_{4} \cdot 7 \mathrm{H}_{2} \mathrm{O}$, $1.5 \mathrm{~g}$ agar and distilled water up to $100 \mathrm{~mL}$. The DG-18 to fungal isolate additionally contained: rose bengal $(2.5 \mathrm{mg} / 100 \mathrm{~mL})$ to restrict colony spreading without affecting spore germination and streptomycin $(30 \mathrm{mg} / 100 \mathrm{~mL})$ to inhibit bacterial growth. The samples were dispersed in physiological saline solution, dilution series prepared and plating in DG-18 to fungal isolate agar plates and were then incubated at $25^{\circ} \mathrm{C}$. Two of the most frequent fungi observed were selected considering their characteristics according to bibliographic data and kept at $4{ }^{\circ} \mathrm{C}$ in DG-18 agar slants. These fungi were identified based on their micro and macro-morphological characteristics, using standard taxonomic keys [35]. Optic microscopy was employed in order to identify the fungi by the observation of their characteristics structures [36]. The fungi were recovered and growth in DG- 18 at $25^{\circ} \mathrm{C}$ for $20-25$ days before used.

\subsection{Antifungal activity}

Fungal spores were removed from the DG-18 agar and suspended in $0.85 \% \mathrm{p} / \mathrm{v} \mathrm{NaCl}$ and $0.005 \% \mathrm{p} / \mathrm{v}$ Tween 20 solution; the concentration of the suspension was adjusted employing a Neubauer chamber to $10^{6}$ spores/mL [29].

Petri dishes containing the selected NP and DG-18 agar were inoculated with $20 \mu \mathrm{L}$ of the spores' suspension. The concentration of the NP was $1 \times 10^{-4} \mathrm{M}$. Besides, dishes without NP were prepared as control.

Fungal growth at $25^{\circ} \mathrm{C}$ was evaluated every week during 1 month as the average diameter of the colony [37,38]. The relative growth inhibition was calculated by percentage, using the following formula [39]:

Inhibition $(\%)=\left(1-\frac{\text { Radial growth with NP }}{\text { Radial growth of control }}\right) \times 100$

\subsection{Paint bio-resistance assay}

The NP were added to a commercial acrylic water-based wall and ceiling paint (Borgolotex ${ }^{\circledR}, 25.2 \%$ of resin, by weight) in a high speed disperser. The concentration studied at the beginning was $5.8 \mathrm{mg} / 100 \mathrm{~g}$ of paint. Then, given the good results, in the case of $\mathrm{AgA}, \mathrm{AgG}$ and $\mathrm{Cu} \mathrm{NP}$, it was decided to test lower concentrations $(0.64$ and $1.90 \mathrm{mg} / 100 \mathrm{~g})$. In the case of $\mathrm{ZnO}$, the results were not so good so it was decided to test a higher concentration $(9.6 \mathrm{mg} / 100 \mathrm{~g})$.

Glass slides $(7.5 \mathrm{~cm} \times 2.5 \mathrm{~cm})$ were wiped with ethanol, dried under laboratory conditions (65\% relative humidity and $25^{\circ} \mathrm{C}$ of temperature) and painted with the tested paints, by brush, on one side. Two layers of paint were applied. The painted slides were kept under laboratory condition for 15 days before testing. Also a series was painted with the acrylic paint without NP, as controls.

Before inoculating with the selected fungi, the painted glasses were cut in squared pieces $(2.5 \mathrm{~cm} \times 2.5 \mathrm{~cm})$ and irradiated with a germicide UV Phillips lamp ( $20 \mathrm{~W}$ ) for $40 \mathrm{~min}$ each side to superficial decontamination [14]. Samples thus obtained were placed in plates containing minimum mineral media before solidification with the painted side up. Therefore the level of the culture medium 
matches the thickness of the glasses. This poor media, chosen to enhance fungi growth on the paint and to use cellulose thickener as carbon source, contains: $5 \mathrm{~g} \mathrm{NaCl}, 1 \mathrm{~g} \mathrm{HK} \mathrm{HO}_{4}, 1 \mathrm{~g}\left(\mathrm{NH}_{4}\right) \mathrm{H}_{2} \mathrm{PO}_{4}, 1 \mathrm{~g}$ $\left(\mathrm{NH}_{4}\right)_{2} \mathrm{SO}_{4}, 0.2 \mathrm{~g} \mathrm{MgSO}_{4}, 3 \mathrm{~g} \mathrm{KNO}_{3}, 15 \mathrm{~g}$ agar and distilled water up to $1000 \mathrm{~mL}$. Fungal inoculums of each isolate were prepared in the same condition than the section above. A $50 \mu \mathrm{L}$ aliquot of each spore suspensions was distributed homogenously all over the painted surface. Fungi growth was followed during 1 month and evaluated at the 4th week employing the ASTM D 5590-00 standard [29]. This standard states that the growth on specimens corresponding to: none, trace of growth ( $<10 \%)$, light growth (10-30\%), moderate growth (30-60\%), heavy growth (60-100\%) rating as $0,1,2,3$, and 4 , respectively [29].

\subsection{Observation by scanning electron microscope (SEM)}

The painted glasses exposed to the fungi for 4 weeks in the bioresistance assay were observed by SEM. The selected ones were those presented better results and the respective controls. In order to proceed with the observation of the superficial responds of the coatings against the fungal development, the samples were removed from the plates with tweezers. After that, the remains of culture medium were eliminated from the bottom and the samples were cut into squares approximately of $10 \mathrm{~mm}$ side. The microscope employed was a Philips FEI Quanta 200, which allows working in low vacuum conditions $\left(10^{-2}-1\right.$ Torr) thereby the samples not require being dehydrated. This technique allows a better keeping of the morphology of the fungal biofilm.
Table 1

Approximate relationship between visual assessment and $\Delta E$ differences.

\begin{tabular}{cl}
\hline$\Delta E$ & Assessment of color differences \\
\hline$<0.2$ & No visible \\
$0.2-0.5$ & Very slightly \\
$0.5-1.5$ & Slightly \\
$1.5-3.0$ & Evident \\
$3.0-6.0$ & Very evident \\
$6.0-12.0$ & Big \\
$>12.0$ & Very big \\
\hline
\end{tabular}

\subsection{Gloss and color measurements}

CIElab color parameters were evaluated on dried paints and compared with the paint without NP. The CIElab diagram represents the area where all the real colors are placed, according to the CIElab transformation. In the center, the luminosity of the color is placed, the vertical axis $L$. $L$ varies from 0 to 100 (white). The other two orthogonal axis form the chromaticity plane, represented by $a$ and $b$. This is based on the opponents color criteria, the variation magenta-bluegreen $(a)$ and yellow-blue $(b)$.

$\Delta E$, the change of color, was calculated as [40]:

$$
\Delta E=\sqrt{\left(L-L_{\mathrm{NP}}\right)^{2}+\left(a-a_{\mathrm{NP}}\right)^{2}+\left(b-b_{\mathrm{NP}}\right)^{2}}
$$

being $L, a$ and $b$ the CIElab parameters for the control paint and $L_{\mathrm{NP}}$, $a_{\mathrm{NP}}$ and $b_{\mathrm{NP}}$, the corresponding ones for the paints with nanoparticles. In Table 1 , the relation between visual assessment and $\Delta E$ differences can be seen.

\section{a)}

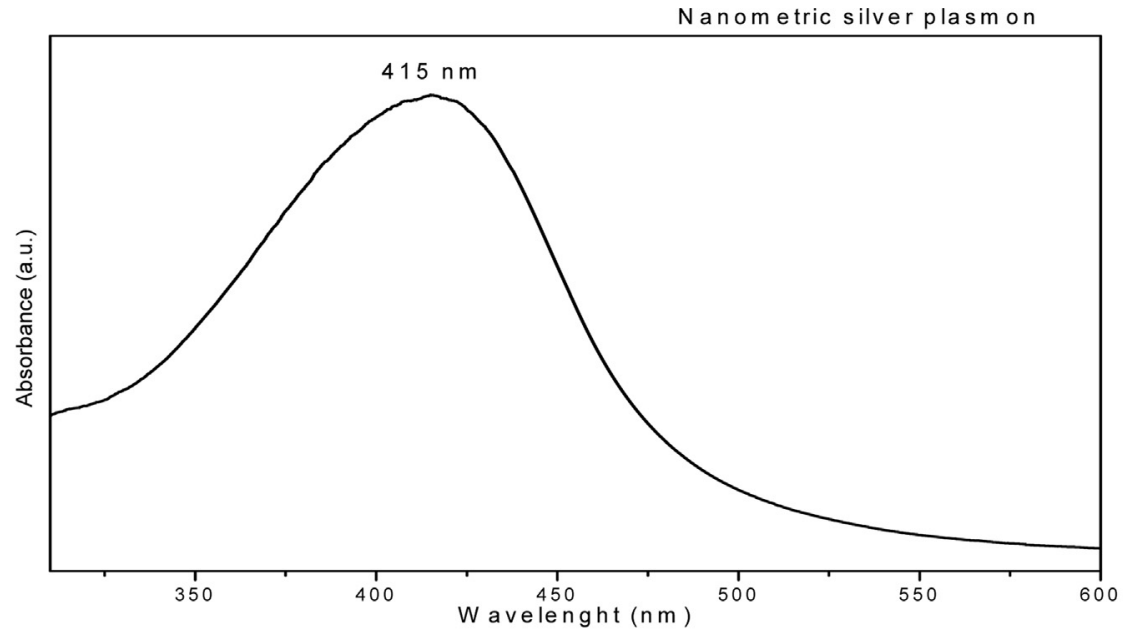

b)

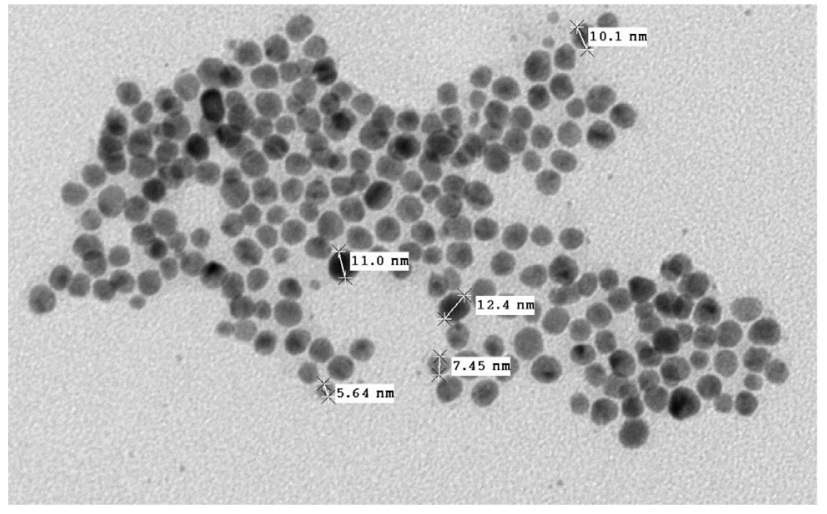

c)

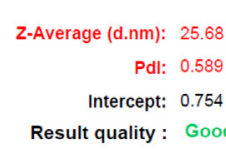

$\%$ Number Width $(\mathrm{nm})$ $100.0 \quad 2.584$

$0.0 \quad 0.000$ $0.0 \quad 0.000$

Fig. 1. (a) Absorption spectra, (b) transmission electron microscope image and (c) size distribution, of quasi-spherical $10 \mathrm{~nm}$ silver nanoparticles (AgA). 
Gloss parameter was also measured.

The measurements were done employing a ByK Gardner glossmeter.

\section{Results and discussion}

\subsection{Nanoparticles characterization}

Silver shows an absorption band in an interval close to the ultraviolet, around $400 \mathrm{~nm}$ and $430 \mathrm{~nm}$ [41], with this information it can be confirmed the obtention of nanometric silver through UV-visible spectroscopy.

Fig. 1 shows the characterization of silver nanoparticles Ag. Fig. 1a, shows the absorption spectra of AgA obtaining as a result, a characteristic band situated at $415 \mathrm{~nm}$. Fig. $1 \mathrm{~b}$ is a transmission electron microscope (TEM) image where a quasi-spherical morphology can be appreciated with a size of $10 \mathrm{~nm}$. Fig. 1c shows the size distribution of the silver nanoparticles, where the average size is $9.98 \mathrm{~nm}$ which corresponds to the TEM images. In the case of $\mathrm{AgG}$, the results indicated an averaged size of $62 \mathrm{~nm}$. Through these results, the morphology and size distribution can be assured.

Due to its metallic properties, copper also absorbs energy from the electromagnetic spectra in the UV-visible interval with a plasmonic resonance effect. In Fig. 2a, this characteristic plasmonic resonance, located at $560 \mathrm{~nm}$ can confirm the existence of metallic copper nanoparticles. This peak position depends upon the size of the particle and shifts to the left as the particle decreases in size according to Yeshchenko et al. [42]. In order to confirm size, size distribution, presence of agglomerates in aqueous solution and morphology, TEM images of the nanoparticles were obtained and DLS measurements were taken. Fig. $2 \mathrm{~b}$ shows the possible presence of agglomerates, the sample was positioned on top of a polymeric substrate in a dry environment and the size obtained was $20 \mathrm{~nm}$. According to the DLS results, the $20 \mathrm{~nm}$ nanoparticles cannot be distinguished due to the presence of agglomerates, shown in Fig. 2b, therefore the DLS equipment measures the agglomerates which result in a size range from 50 to $100 \mathrm{~nm}$ (Fig. 2c)).

TEM image of ZnO nanoparticles (Fig. 3) shows particles around $40-50 \mathrm{~nm}$; the morphology is quasi-spherical and small agglomerates are observed along with the coating added during the synthesis. XRD was also performed (diffractogram not shown in this report) confirming the obtention of zinc oxide.

\subsection{Fungal isolates and antifungal activity}

The fungal isolates selected to the tests performed were $A$. alternata and $C$. globosum for their ability to grow on paint films and negative impact on human health $[30,31]$.

Table 2 shows the inhibition of the fungal growth (\%) after a week of incubation. It can be observed that the inhibitive activity of AgA was higher compared with the other NP at the test concentration.

Fig. 4 shows the dishes of the agar with AgA incubated for 1 week (1a and 1c) and the ones corresponding to the control dishes

a)
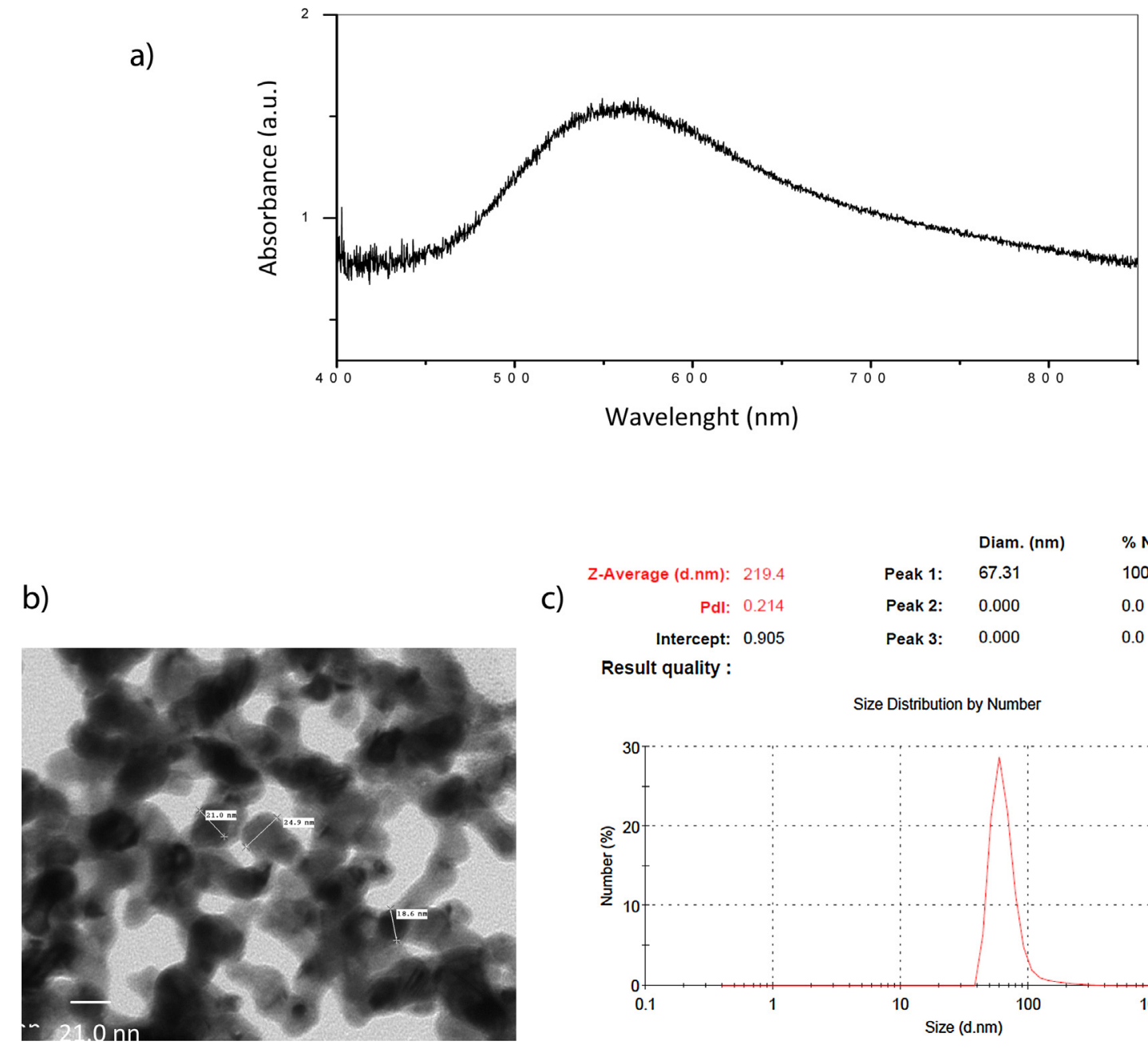

$\begin{aligned} \text { Z)-Average (d.nm): } & 219.4 \\ \text { Pdl: } & 0.214 \\ \text { Intercept: } & 0.905\end{aligned}$

Result quality :

$\begin{array}{llll} & \text { Diam. }(\mathrm{nm}) & \text { \% Number } & \text { Width }(\mathrm{nm}) \\ \text { Peak 1: } & 67.31 & 100.0 & 28.99 \\ \text { Peak 2: } & 0.000 & 0.0 & 0.000 \\ \text { Peak 3: } & 0.000 & 0.0 & 0.000\end{array}$

Size Distribution by Number

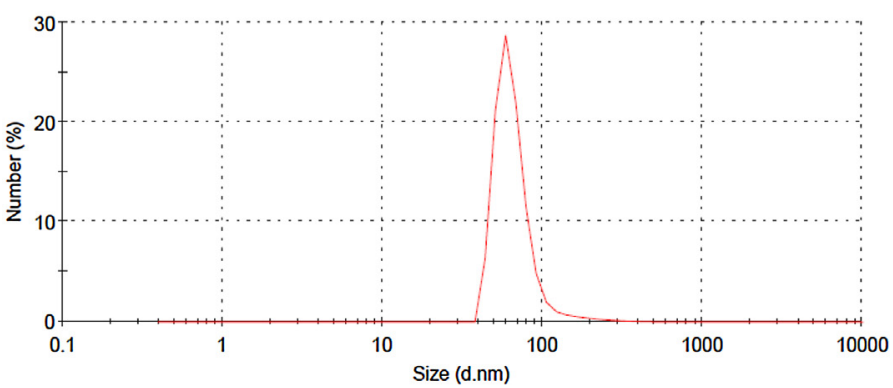

Fig. 2. (a) Absorption spectra, (b) transmission electron microscope image and (c) size distribution, of copper nanoparticles. 


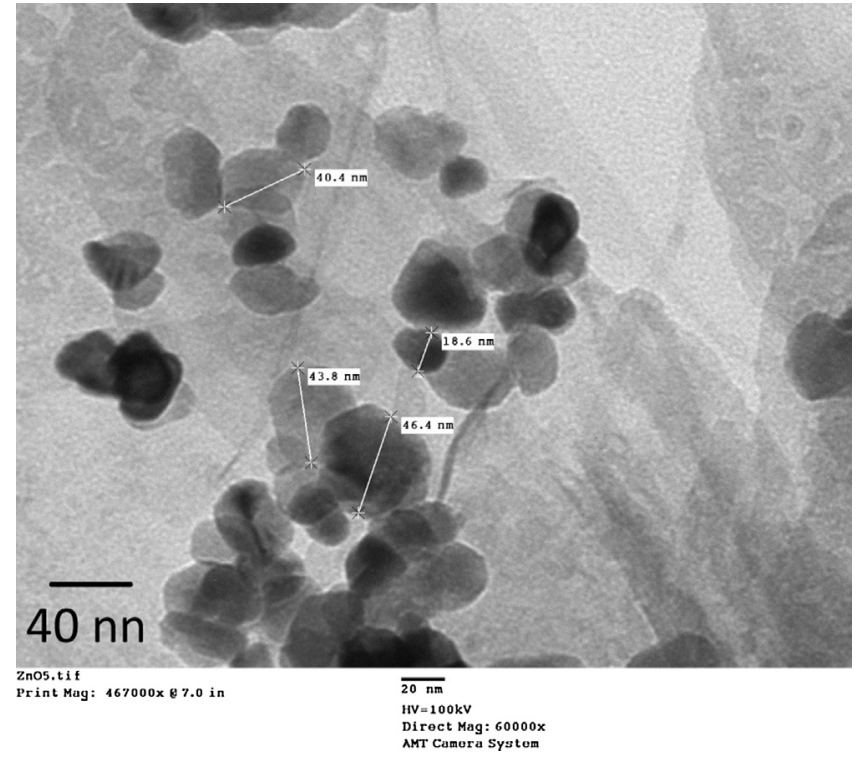

Fig. 3. Transmission electron microscope image of zinc oxide nanoparticles.

Table 2

Antifungal activity (until a week).

\begin{tabular}{llllrl}
\hline \multirow{2}{*}{ Fungi } & \multicolumn{4}{l}{ \% Inhibition } \\
\cline { 2 - 6 } & $\mathrm{AgA}$ & $\mathrm{AgG}$ & $\mathrm{Cu}$ & $\mathrm{ZnO}$ & Control \\
\hline Alternaria alternate & 89.0 & 13.6 & 4.8 & 11.5 & 0.0 \\
Chaetomium globosum & 100.0 & 11.0 & 1.5 & 5.3 & 0.0 \\
\hline
\end{tabular}

(1b and 1d) with both fungi. It can be seen that, under the concentration employed, this NP inhibited fungal growth very efficiently. The others NP presented less inhibition (Table 2).

\subsection{Paints bio-resistance assays}

The fungal resistance to the lowest NP concentration coatings $(0.64 \mathrm{mg} / 100 \mathrm{~g})$ was poor, however when the concentration of the NP was increased, better inhibitions results were obtained, especially when AgA NP were employed (Table 3). The coatings with $5.8 \mathrm{mg} / 100 \mathrm{~g}$ of $\mathrm{AgA}$ and $\mathrm{AgG}$ were the most efficient ones. In the case of $\mathrm{ZnO} \mathrm{NP}$ both concentrations used gave unfavorable results, abundant growth after 4 weeks of incubation.

It has to be remarked that according to these results, A. alternata is more resistant than C. globosum to the tested NP.

Fig. 5 shows in detail the results obtained in the paint bioresistance assay after 4 weeks with paint containing AgA NP.

In the case of the paints with silver, the results obtained indicate that the antifungal activity is influenced by the size of the nanoparticles. The decreased of the NP size increased the surface
Table 3

Evaluation of the fungi growth degree on paints by ASTM D5590-00 (4th week).

\begin{tabular}{|c|c|c|c|c|c|c|c|c|}
\hline \multirow[t]{3}{*}{ Coatings ${ }^{c}$} & \multicolumn{8}{|c|}{ Concentration $\mathrm{mg} / 100 \mathrm{~g}$ of paint } \\
\hline & \multicolumn{2}{|c|}{0.64} & \multicolumn{2}{|c|}{1.92} & \multicolumn{2}{|l|}{5.8} & \multicolumn{2}{|l|}{9.6} \\
\hline & $\mathrm{Cg}^{\mathrm{a}}$ & $A a^{\mathrm{b}}$ & $\mathrm{Cg}$ & $A a$ & $\mathrm{Cg}$ & $A a$ & $\mathrm{Cg}$ & $A a$ \\
\hline AgA & 3 & 4 & 2 & 3 & 1 & 2 & - & - \\
\hline AgG & 4 & 4 & 3 & 3 & 2 & 3 & - & - \\
\hline $\mathrm{Cu}$ & 4 & 4 & 4 & 4 & 3 & 3 & - & - \\
\hline $\mathrm{ZnO}$ & - & - & - & - & 4 & 4 & 4 & 4 \\
\hline
\end{tabular}

available to interact with the fungal cellular membrane. The adhesion of the NP to the membrane can modify its properties increasing the membrane permeability [43].

In none of the NP-containing paints an inhibition halo surrounding the painted glasses was observed, suggesting that the biocide was retained in the paint. This result indicates that the biocide potentially would not be leached from the paint, increasing the paint useful life [23].

\subsection{Observation by SEM of the paint films}

In Figs. 6 and 7, the SEM microphotographs of the paint that resulted more efficient ( $5.8 \mathrm{mg}$ of $\mathrm{AgA} / 100 \mathrm{~g}$ of paint), taken after 4 weeks of assay are showed. Fig. 6a and d correspond to noninoculated paints, so they do not present fungal development but it can be seen that the control painted surface (Fig. 6a) is more heterogeneous than the one with AgA paint (Fig. 6d).

The microphotographs of the $C$. globosum inoculated control panels are showed in Fig. $6 \mathrm{~b}$ and c. They showed an active growth of the mycelium, in an important hyphae network that extends all over the surface beside a great number of spores (showed in detail with the white arrow). In Fig. $6 c$, it can be seen with better detail the interaction between the hyphae and the paint, being this invasive, the mycelium can break the integrity of the paint as it penetrate the paint film (white arrows on the microphotograph). These observations contrast notably with the ones of AgA paint, where spore germination and hyphae development was inhibited therefore no breakdown of the film was observed, Fig. 6e. The spores observed on the surface might be those that were deposited to perform the assay, as no fungal growth can be seen. Fig. 6 f shows in detail how the presence of AgA NP would have produced some changes in the spore surface, marked by the white arrows.

The paints inoculated with $A$. alternata showed, as those with $C$. globosum, an abundant mycelium (pointing out with white arrows) occurred on the surface of the control paint (Fig. 7a) which can be seen with more detail in the following microphotograph (Fig. 7b) much more reduce development occurred on AgA paint (Fig. 7c).
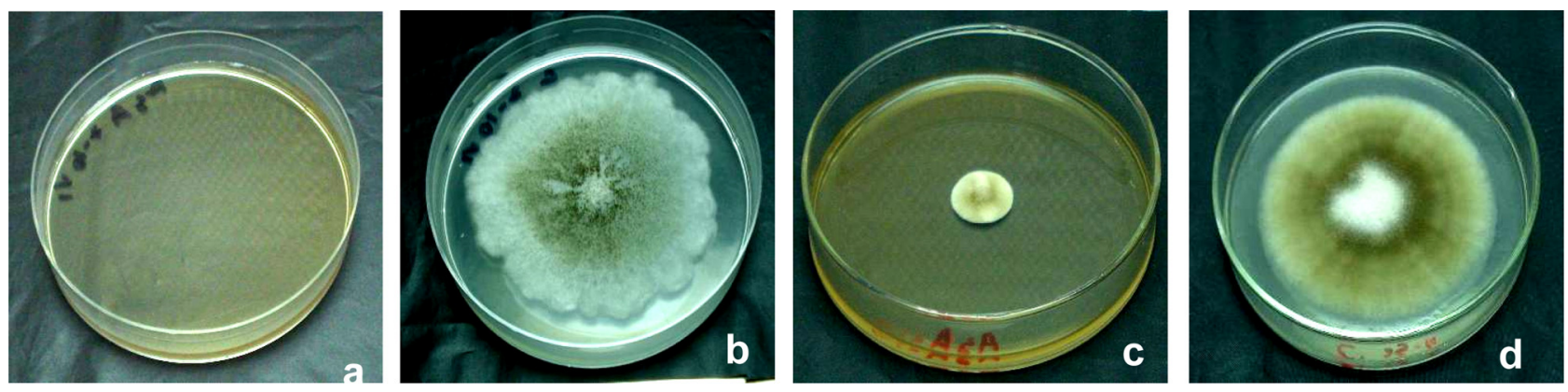

Fig. 4. Chaetomium globosum (a and b) and Alternaria alternata (c and d) in solid media with $\operatorname{AgA}(\mathrm{a}$ and c) and without NP (b and d). 


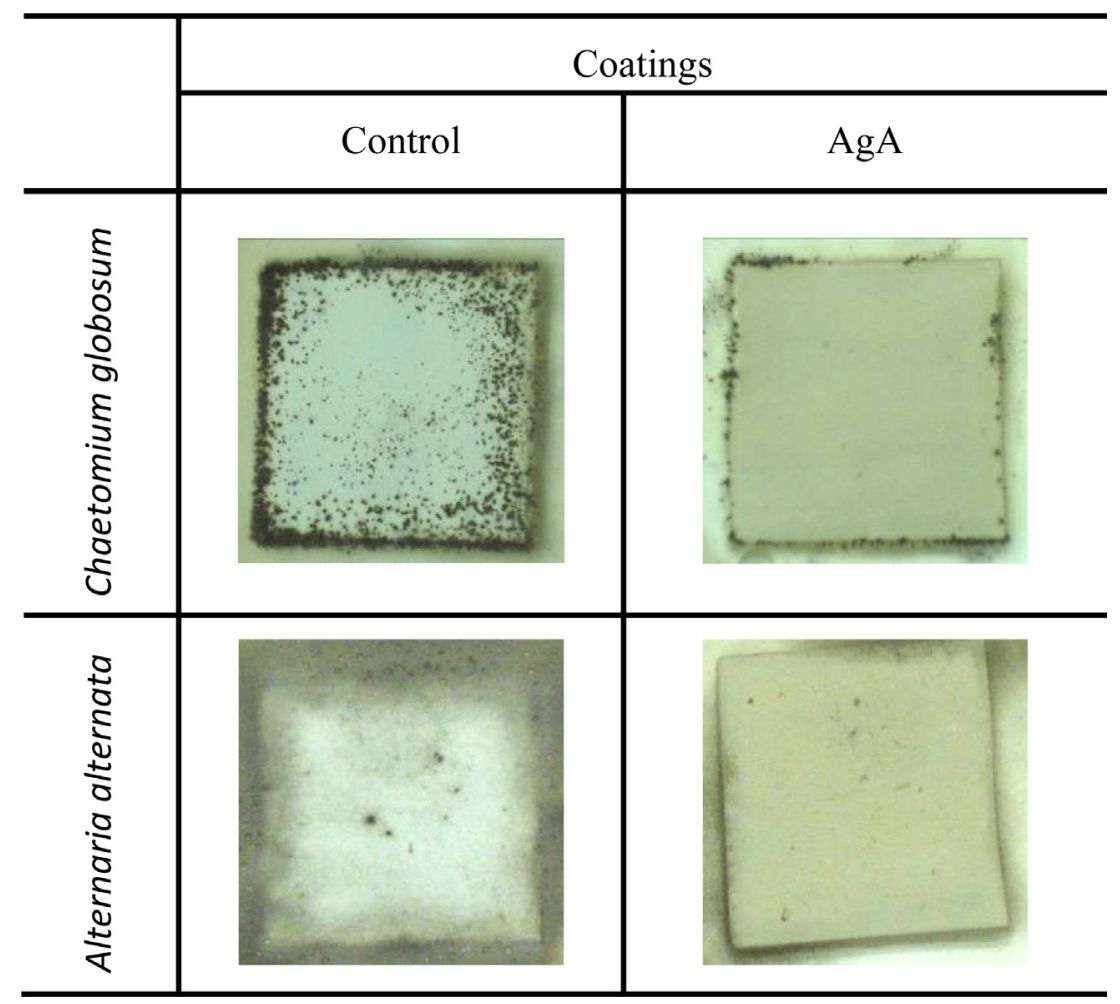

Fig. 5. Bioresistance essay with Chaetomium globosum and Alternaria alternata after 4 weeks.

a

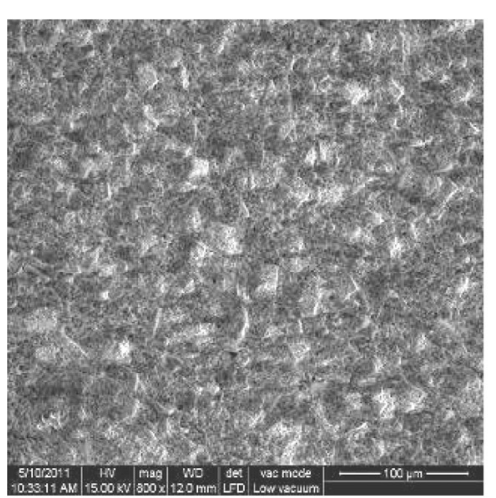

d

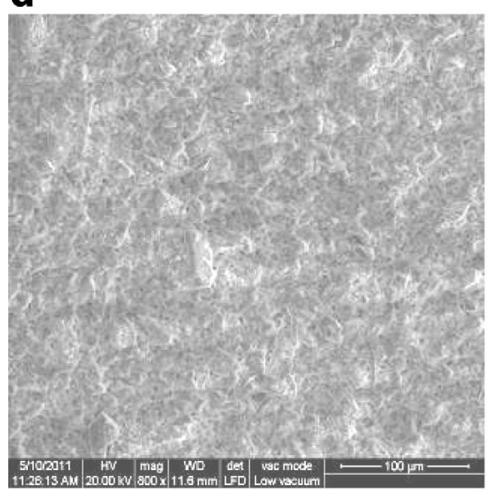

b

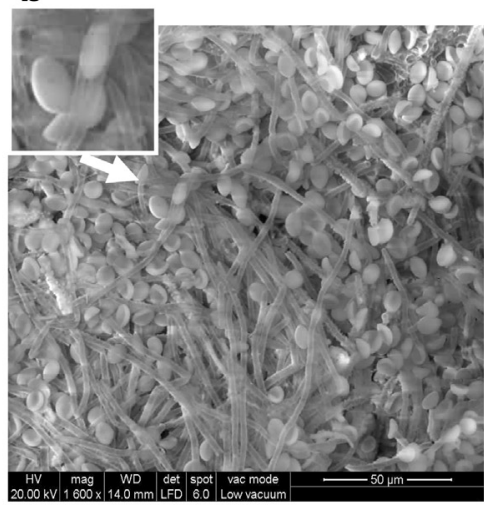

e

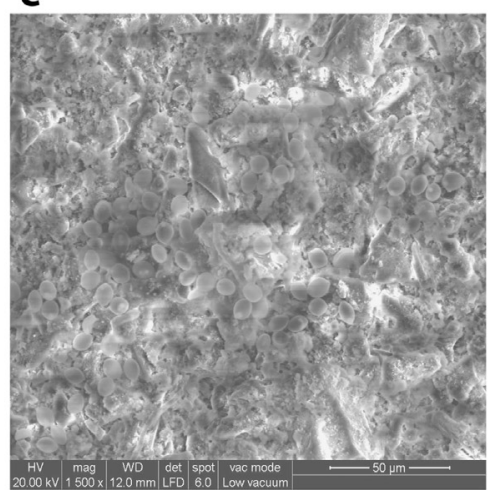

C

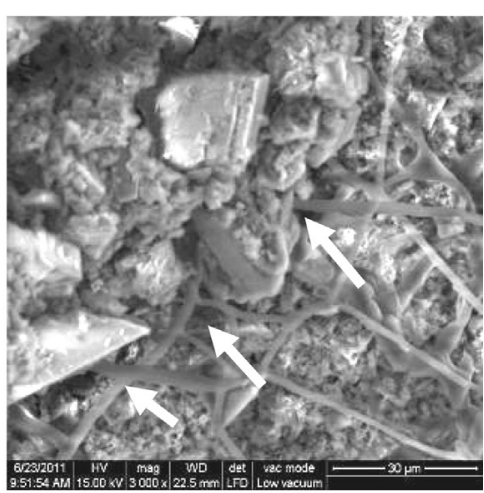

f

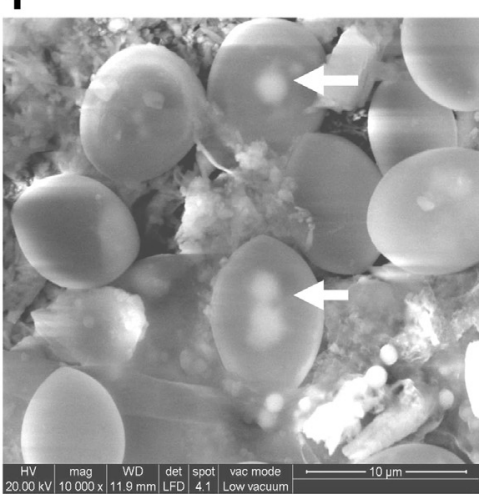

Fig. 6. SEM Microphotographs: non-inoculated control paint (a); control paint exposed to Chaetomium globosum growth (b and c); non-inoculated paint with AgA (d); paint with AgA exposed to Chaetomium globosum growth (e and f). 


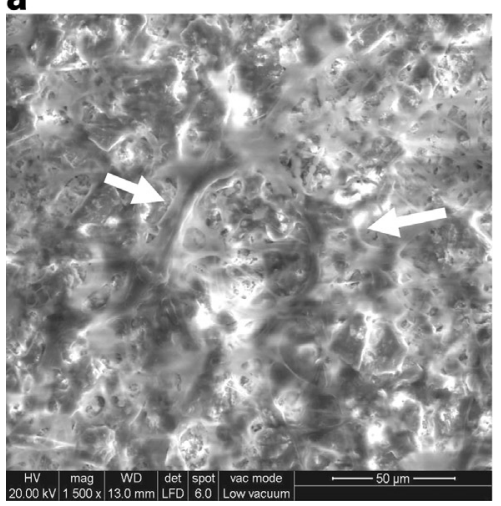

b

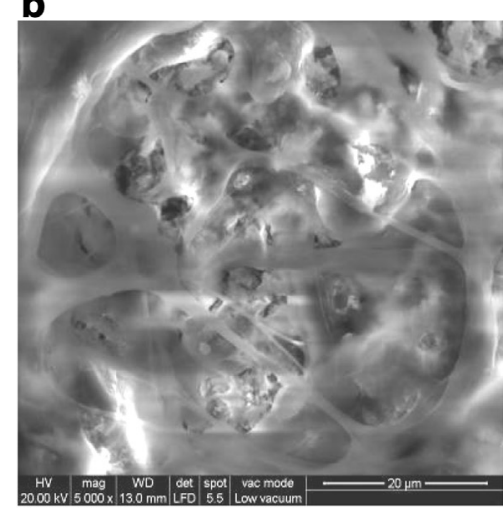

c

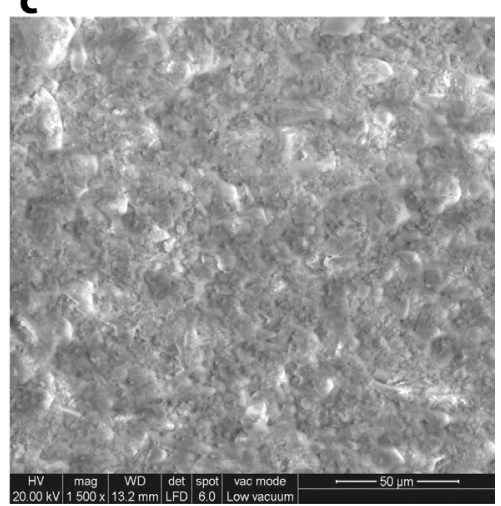

Fig. 7. SEM Microphotographs of the films of control paint ( $a, b)$ and with $\operatorname{AgA}(c)$ exposed to Alternaria alternata.

Table 4

Color changes $(\Delta E)$.

\begin{tabular}{lllll}
\hline Coatings & \multicolumn{4}{l}{ Concentration $\mathrm{mg} / 100 \mathrm{~g}$ of paint } \\
\cline { 2 - 5 } & 0.64 & 1.92 & 5.8 & 9.6 \\
\hline $\mathrm{AgA}$ & 0.5 & 4.5 & 12.7 & - \\
$\mathrm{AgG}$ & 4.6 & 6.4 & 6.6 & - \\
$\mathrm{Cu}$ & 2.1 & 1.6 & 1.0 & - \\
$\mathrm{ZnO}$ & - & 0.9 & 1.7 & 1.4 \\
\hline
\end{tabular}

\subsection{Gloss and color measurements}

Neither the brightness nor the CIElab parameters of the paints changed significantly with the addition of the nanoparticles, except in the case of $\mathrm{AgA}$ and $\mathrm{AgG}$ with the highest concentrations (Tables 1 and 4), being more important in the case of the silver NP with bigger size. The B parameter (gloss) for all the paints was around 2.0.

\section{Conclusions}

Silver, copper and zinc oxide nanoparticles inhibit the growth of $C$. globosum and A. alternata in agar plate assays, being $10 \mathrm{~nm}-$ size-silver nanoparticles the more efficient one.

When the nanoparticles were included in paint and tested against the same fungi, the inhibition efficiency increased as the concentration of the nanoparticles is increased, except in the case of $\mathrm{ZnO}$ which did not inhibit fungi growth with neither tested concentrations. Besides, no halo appeared around the painted glass indicating that there would not be a migration of the biocide from the paint film; this would extend paint useful life. Moreover, the gloss of the paints did not change with the addition of the nanoparticles while color changes only appeared in the case of higher concentrations of silver.

It will be subject of another work to properly adjust the concentration of $\mathrm{ZnO}$ necessary to achieve greater inhibition of fungal growth.

\section{Acknowledgements}

The authors are grateful to Consejo Nacional de Investigaciones Científicas y Técnicas (CONICET), Comisión de Investigaciones Científicas de la Provincia de Buenos Aires (CICPBA), Agencia Nacional de Promoción Científica y Tecnológica (ANPCyT) and to Universidad Nacional de La Plata (UNLP), Ministerio de Ciencia, Tecnología e Innovación Productiva for sponsor this research work. This study was partially supported by the Consejo Nacional de Ciencia y Tecnología (CONACyT) Grant C005-189530 and CB-2010-01-153675.

\section{References}

[1] Environmental Protection Agency (EPA), Indoor Environments Division (IED), Mold Remediation in Schools and Commercial Buildings, 2008, www.epa.gov/mold

[2] E. Bloom, L.F. Grimsley, C. Pehrson, J. Lewis, L. Larsson, Molds and mycotoxins in dust from water-damaged homes in New Orleans after hurricane Katrina, Indoor Air 19 (2009) 153-158.

[3] A. Adhikari, J.Jung, T. Reponen, J. Lewis, E.C. DeGrasse, F.L. Grimsley, G.L. Chewd, S.A. Grinshpun, Aerosolization of fungi (1-3)-b-D-glucanandendotoxin from flood-affected materials collected in New Orleans homes, Environ. Res. 109 (2009) 215-224

[4] World Health Organization (WHO) Regional Office for Europe, WHO Guidelines for Indoor Air Quality: Dampness and Mould, 2009, http://www.euro.who. int/data/assets/pdf_file/0017/43325/E92645.pdf

[5] M.A. Shirakawa, C. Gaylarde, P. Gaylarde, V. John, W. Gambale, Fungal colonization and succession on newly painted buildings and the effect of biocide, FEMS Microb. Ecol. 39 (2002) 165-173.

[6] J.D. Cooley, W.C. Wong, C.A. Jumper, D.C. Straus, Fungi and the indoor environment: their impact on human health, Adv. Appl. Microbiol. 55 (2009) 1-30.

[7] Z. Cao, Y. Sun, Polymeric N-halamine latex emulsions for use in antimicrobial paints, ACS Appl. Mater. Interfaces 1 (2009) 494-504.

[8] P.S. Guiamet, H.A. Videla, Microbiological spoilage of aqueous based surface coatings, Corros. Rev. 14 (1996) 47-58.

[9] K. Johns, Hygienic coatings: the next generation, Surface Coat. Int. B: Coat. Trans. 86 (2003) 101-110

[10] K. Harada, A. Hasegawa, C.N. Wei, K. Minamoto, Y. Noguchi, K. Hara, O. Matsushita, K. Noda, A. Ueda, A review of indoor air pollution and health problems from the viewpoint of environmental hygiene: focusing on the studies of indoor air environment in Japan compared to those of foreign countries, J. Health Sci. 56 (2010) 488-501.

[11] D. Allsopp, K. Seal, C. Gaylarde, Introduction to Biodeterioration, Press Syndicate of the University of Cambridge, Cambridge, United Kingdom, 2004.

[12] D. Vaughan-Lee, Cleaning up the act, Polym. Paint Colour J. (4455) (2002) 24-26.

[13] C. Hare, Microbiologically-influenced attack of coatings, J. Phys. Chem. Lett (September) (2000) 51-65.

[14] N. Bellotti, L. Salvatore, C. Deyá, M.T. Del Panno, B. del Amo, R. Romagnoli, The application of bioactive compounds from the food industry to control mould growth in indoor waterborne coatings, Colloids Surf. B: Biointerfaces 104 (2013) 140-144.

[15] A.E. Aiello, E.L. Larson, What is the evidence for a causal link between hygiene and infections, Lancet Infect. Dis. 2 (2002) 103-110.

[16] A. Kramer, I. Schwebke, G. Kampf, How long do nosocomial pathogens persist on inanimate surfaces? A systematic review, BMC Infect. Dis. 6 (2006) $130-138$.

[17] J.M. Boyce, Environmental contamination makes an important contribution to hospital infection, J. Hosp. Infect. 65 (2007) 50-54.

[18] M. Moritz, M. Geszke-Moritz, The newest achievements in synthesis, immobilization and practical applications of antibacterial nanoparticles, Chem. Eng. J. 228 (2013) 596-613.

[19] R.D. Holtz, B.A. Lima, A.G. Souza Filho, M. Brocchi, O.L. Alves, Nanostructured silver vanadate as a promising antibacterial additive to water-based paints, Nanomed.: Nanotechnol. Biol. Med. 8 (2012) 935-940.

[20] M.J. Hanus, A.T. Harris, Nanotechnology innovations for the construction, Ind. Prog. Mater. Sci. 58 (2013) 1056-1102. 
[21] W.R. Li, X.B. Xie, O.S. Shi, S.S. Duan, Y.S. Ouyang, Y.B. Chen, Antibacterial effect of silver nanoparticles on Staphylococcus aureus, Biometals 24 (2011) 135-141.

[22] C.N. Lok, C.M. Ho, R. Chen, Q.Y. He, W.Y.Yu, H. Sun, P.K. Tam, J.F. Chiu, C.M. Chen, Proteomic analysis of the mode of antibacterial action of silver nanoparticles, J. Proteome Res. 5 (2006) 916-924.

[23] M. Rai, A. Yadav, A. Gade, Silver nanoparticles as a new generation of antimicrobials, Biotechnol. Adv. 27 (2009) 76-83.

[24] M. Moritz, M. Geszke-Moritz, The newest achievements in synthesis, immobilization and practical applications of antibacterial nanoparticles, Rev. Chem. Eng. J. 228 (2013) 596-613.

[25] S.T. Khan, M. Ahamed, A. Al-Khedhairy, J. Musarrat, Biocidal effect of copper and zinc oxide nanoparticles on human oral microbiome and biofilm formation, Mater. Lett. 97 (2013) 67-70.

[26] J. Drelich, B. Li, P. Bowen, J.-Y. Hwang, O. Mills, D. Hoffman, Vermiculite decorated with copper nanoparticles: novel antibacterial hybrid material, Appl. Surf. Sci. 257 (2011) 9435-9443.

[27] L.F. Espinosa-Cristóbal, G.A. Martínez-Castañón, R.E. Martínez-Martínez, J.P. Loyola-Rodríguez, N. Patiño-Marín, J.F. Reyes-Macías, F. Ruiz, Antibacterial effect of silver nanoparticles against Streptococcus mutans, Mater. Lett. 63 (2009) 2603-2606,

[28] E. Haslam, Vegetable tannins - lessons of a phytochemical lifetime, Phytochemistry 68 (2007) 2713-2721.

[29] ASTM D5590-00, Standard Test Method for Determining the Resistance of Paint films and Related Coatings to Fungal Defacement by Accelerated Four-Week Agar Plate Assay, 2010

[30] C. Alexopoulos, C. Mins, Introducción a la micología Ed, OMEGA, Barcelona, 1985.

[31] C.S. Yang, P.A. Heinsohn, Sampling and Analysis of Indoor Microorganisms, John Wiley \& Sons, Hoboken, New Jersey, 2007.

[32] G.A. Martinez-Castañon, N. Nino-Martinez, F. Martinez-Gutierrez, J.R. Martinez-Mendoza, F. Ruiz, Synthesis and antibacterial activity of silver nanoparticles with different sizes, J. Nanopart. Res. 10 (2008) 1343-1348.
[33] M.J. Guajardo-Pacheco, J.E. Morales-Sánchez, J. González-Hernández, F. Ruiz Synthesis of copper nanoparticles using soybeans as a chelant agent, Mater Lett. 64 (2010) 1361-1364

[34] L. Salvatore, R. Romagnoli, B. del Amo, N. Bellotti, M.T. Del Panno, Evaluación de la resistencia de pinturas frente a aislamientos fúngicos, in: Anales del 3er. Enc. Jóv. Inv. Cien. Tec. Mat. SAM. No 11-12, 2010.

[35] R.A. Samson, S. Ellen, E.S. Hoekstra, J.C. Frisvad (Eds.), Introduction to Food- and Airborne Fungi, ASM, Netherlands, 2004.

[36] R.A. Samson, E.S. Hoekstra, J.C. Frisvad, O. Filtenborg (Eds.), Introduction to Food-borne Fungi, 4th ed., Contraalbureau vool Schimmelcultures, Baarn, 1995

[37] S. Marín, A.J. Ramos, V. Sanchis, Comparison of methods for the assessment of growth of food spoilage moulds in solid substrates, Int. J. Food Microbiol. 99 (2005) 329-341.

[38] S. Marín, D. Cuevas, A.J. Ramos, V. Sanchos, Fitting of colony diameter and ergosterol as indicators of food borne mould growth to known growth models in solid medium, Int. J. Food Microbiol. 121 (2008) 139-149.

[39] V.B. Bajpai, S. Shukla, S.C. Kang, Chemical composition and antifungal activity of essential oil and various extract of Silene armeria L., Bioresour. Technol. 99 (2008) 8903-8908

[40] G. Teichmann, The use of colorimetric methods in the concrete industry, Concr Precast. Plant Technol. 11 (1990) 58-73.

[41] S. Shrivastava, T. Bera, A. Roy, G. Singh, P. Ramachandrarao, D. Dash, Characterization of enhanced antibacterial effects of novel silver nanoparticles, Nanotechnology 18 (2007) 1-9.

[42] O.A. Yeshchenko, I.M. Dmitruk, A.M. Dmytruk, A.A. Alexeenko, Influence of annealing conditions on size and optical properties of copper nanoparticles embedded in silica matrix, Mater. Sci. Eng. B 137 (2007) 247-254.

[43] T.M. Tolaymat, A.M. El Badawy, A. Genaidy, K.G. Scheckel, T.P. Luxton, M. Suidan, An evidence-based environmental perspective of manufactured silver nanoparticle in syntheses and applications: a systematic review and critica appraisal of peer-reviewed scientific papers, Soc. Total Environ. 408 (2010) 999-1006. 